\title{
Sodium transport in erythrocytes: differences between normal children and children with primary and secondary hypertension
}

\author{
M UCHIYAMA, V SHAH, C E DAMAN WILLEMS, AND M J DILLON
}

Renal Unit, Hospital for Sick Children, Great Ormond Street, and Department of Paediatric Nephrology, Institute of Child Health, London

SUMMARY The following measurements were made in normal children, children with primary hypertension, and children with secondary hypertension: erythrocyte intracellular sodium concentration, total sodium efflux rate constant, and maximum binding of ouabain to erythrocytes reflecting the number of sodium/potassium adenosine triphosphatase pump sites. Children with primary hypertension had a significantly higher mean erythrocyte intracellular sodium concentration $(8.2$ compared with 6.6 and $6.7 \mathrm{mmol} / \mathrm{l}$ cells $)$, and significantly lower total sodium efflux rate constant $(0.5071$ compared with 0.6983 and 0.6197$)$ and maximum binding of ouabain to erythrocytes $(9 \cdot 1$ compared with 11.7 and $11.0 \mathrm{nmol} / \mathrm{l}$ cells) than normal children and children with secondary hypertension, respectively.

Since the original report by Losse et al in $1960^{1}$ that intracellular sodium was increased in the red blood cells of patients with essential hypertension, various abnormalities of ion transport have been reported in patients with primary hypertension, ${ }^{2-4}$ and it has been postulated that essential hypertension may be caused by disturbance of membrane electrolyte transport. Because it is difficult to study the cells in the walls of blood vessels where abnormalities may affect blood pressure, circulating blood cells-for example, leucocytes and erythrocytes-have been used to study the transport of electrolytes across membranes.

Few studies have been undertaken on transport of sodium across cell membranes in children with hypertension. ${ }^{56}$ We therefore undertook a study of erythrocyte sodium transport in children with primary hypertension and compared the findings with those in normal children and in patients with secondary hypertension.

\section{Subjects and methods}

We studied 15 normal children who acted as controls (range 5-15 years), 12 children with primary hypertension (age range 12-16 years), and 27 children with secondary hypertension (age range 5-15 years). The control children, whose blood was being taken for another reason during the course of investigations of minor illnesses, did not have any family history of hypertension. Children with primary hypertension showed significant increases in blood pressure (greater than the 95th centile for age) on repeated measurements and were not receiving antihypertensive treatment. No other causes for their hypertension were found on thorough examination. All patients with secondary hypertension had renal hypertension, and in most of these the blood pressure was renin dependent. All the children with primary hypertension had normal plasma renin activities for their ages (less than $899 \mathrm{ng}$ angiotensin I///hour or $690 \mathrm{ng}$ angiotensin I///hour. Eight of 27 children with secondary hypertension were receiving treatment; six were receiving propranolol and hydralazine, and two were receiving captopril. The study was approved by the ethical committee of the Hospital for Sick Children and the Institute of Child Health.

Samples of $5 \mathrm{ml}$ of fresh heparinised blood were taken; $2 \mathrm{ml}$ of each were used for measurement of the ${ }^{22}$ sodium efflux, and the remaining $3 \mathrm{ml}$ were separated into plasma and erythrocytes at $3000 \mathrm{rpm}$.

The erythrocyte intracellular sodium concentration was measured by flame photometry with IL 943 flame photometer (Instrumental Laboratory) after washing erythrocytes three times with $155 \mathrm{mmol} / \mathrm{l}$ of cold choline chloride $\left(4^{\circ} \mathrm{C}\right)$. The ${ }^{22}$ sodium efflux rate constant was measured by a modification of the method used by Fitzgibbon et $a l^{7} ; 4.0 \mu \mathrm{Ci}$ of ${ }^{22}$ sodium $(22 \mu \mathrm{Ci} / \mathrm{ml}$, Amersham International) was 
added to $2 \mathrm{ml}$ of whole blood and incubated at $37^{\circ} \mathrm{C}$ for one hour. Labelled erythrocytes were obtained and washed four times with cold isotonic saline. A sample of $250 \mu$ l of packed erythrocytes was added to $500 \mu \mathrm{l}$ of their own plasma, and reincubated at $37^{\circ} \mathrm{C}$ for one hour; $25 \mu \mathrm{l}$ of a cell suspension were taken into counting tubes both before and after this incubation. Finally, $250 \mu \mathrm{l}$ of incubated blood was centrifuged at $12000 \mathrm{rpm}$ for three minutes (Eppendorf microcentrifuge) to obtain $125 \mu \mathrm{l}$ of supernatant for counting.

In each tube ${ }^{22}$ sodium was counted with a LKB gamma counter (1282 Compugamma). The efflux rate constant $(\mathrm{Ke})$ was determined by using the following equation: $1 \mathrm{n}$ (natural $\log )\left(1-\mathrm{N}_{\mathrm{t}} / \mathrm{N}_{\mathrm{o}}\right)=$ -Ket, where $\mathrm{N}_{\mathrm{o}}={ }^{22}$ sodium present/unit volume of suspension of incubating cells (mean of the counts/ unit volume of suspension taken at time $\mathbf{0}$ and $\mathbf{6 0}$ minutes), $\mathrm{N}_{\mathrm{t}}={ }^{22}$ sodium present per unit volume of supernatant at time 60 minutes.

The binding of ouabain to erythrocytes was measured by a modification of the method used by Gardner and Conlon. ${ }^{8}$ Packed erythrocytes, which were washed three times with cold isotonic saline $\left(4^{\circ} \mathrm{C}\right)$, were resuspended in trometamol (TRIS) buffer (sodium chloride $130 \mathrm{mmol} / \mathrm{l}$, sucrose 20 $\mathrm{mmol} / \mathrm{l}$, glucose $10 \mathrm{mmol} / \mathrm{l}$, and TRIS $10 \mathrm{mmol} / \mathrm{l}$, $\mathrm{pH} 7 \cdot 4)$ to a packed cell volume of $0 \cdot 15$. A stock solution of ouabain $(100 \mathrm{mmol} / \mathrm{l}$ in $10 \%$ ethanol) was prepared and kept at $4^{\circ} \mathrm{C}$.

A sample of $100 \mu \mathrm{l}$ of ${ }^{3} \mathrm{H}$ ouabain $(37 \mathrm{Ci} / \mathrm{ml}$, Amersham International) was placed into a glass tube and evaporated under nitrogen. The residue was redissolved with $500 \mu \mathrm{l}$ of isotonic saline, of which $100 \mu \mathrm{l}$ was diluted in $2.6 \mathrm{ml}$ of isotonic saline on assay. Two fold serial dilutions were then made four times. Of the erythrocyte suspension, $300 \mu \mathrm{l}$ were incubated with $50 \mu \mathrm{l}$ of the diluted radioactive ouabain at each dilution, and with $50 \mu \mathrm{l}$ of isotonic saline or $1 \mathrm{mmol} / \mathrm{l}$ of cold non-radioactive ouabain at $37^{\circ} \mathrm{C}$ for two hours. Subsequently the unbound ouabain was removed by washing three times with isotonic saline, and the final pellet resuspended in $200 \mu \mathrm{l}$ of $10 \%$ trichloroacetic acid. After centrifuging $100 \mu \mathrm{l}$ of its supernatant was used for liquid scintillation counting (LKB; 1210 Ultrobeta) in $3 \mathrm{ml}$ of Cocktail T (British Drug Houses).

Non-specific binding was estimated by replacing $50 \mu \mathrm{l}$ of isotonic saline with $50 \mu \mathrm{l}$ of $1 \mathrm{mmol} / \mathrm{l}$ of cold ouabain. The amount of ouabain specifically bound was calculated by subtracting the non-specific counts from the total counts. Maximum binding of ouabain to erythrocytes was calculated using a curve fitting computer programme. All determinations were calculated in duplicate.

Intra-assay coefficients of variation were $2.4 \%$,
$3.6 \%$, and $6 \cdot 2 \%$ for intracellular sodium concentration, total sodium efflux rate constant, and maximum binding of ouabain to erythrocytes, respectively. Results were expressed as mean (SEM) and analysed parametrically by the unpaired Student's $t$ test.

\section{Results}

In the children with primary hypertension, mean erythrocyte intracellular sodium concentration was significantly higher $(8.2(0.63) \mathrm{mmol} / \mathrm{l}$ cells $)$ than in

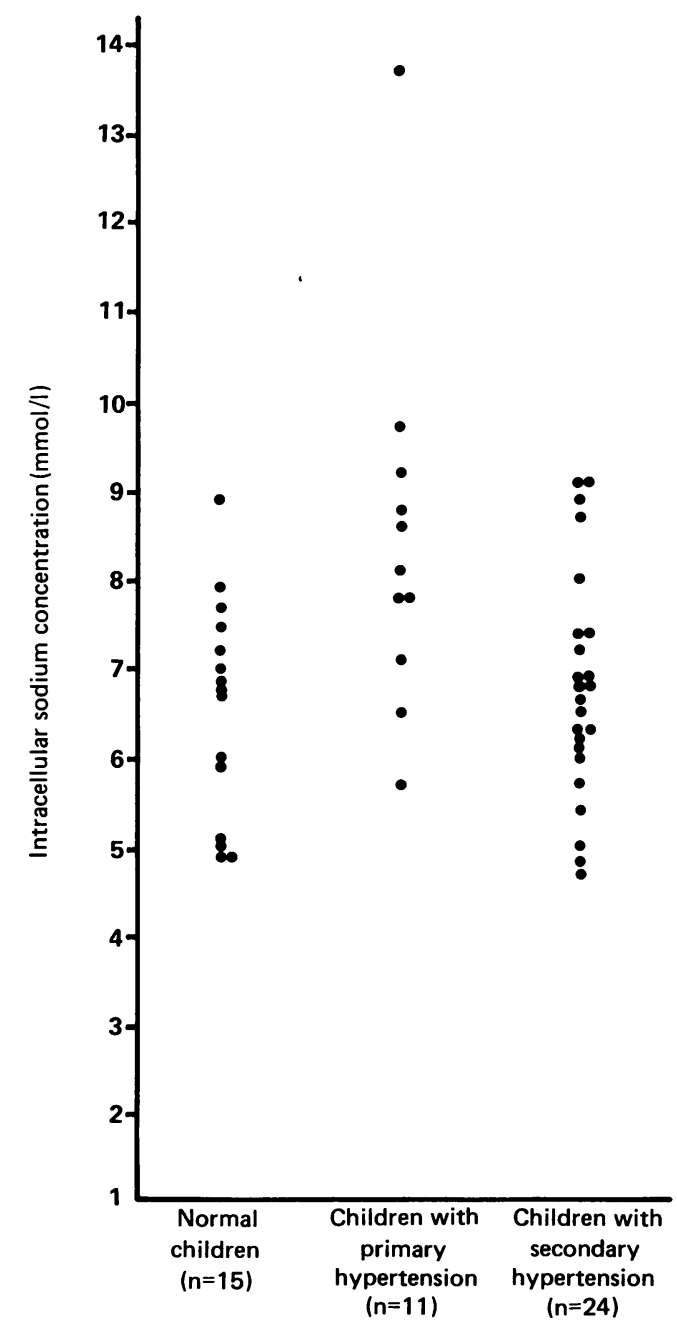

Fig 1 Intracellular sodium concentration in erythrocytes from normal children, children with primary hypertension, and children with secondary hypertension. 


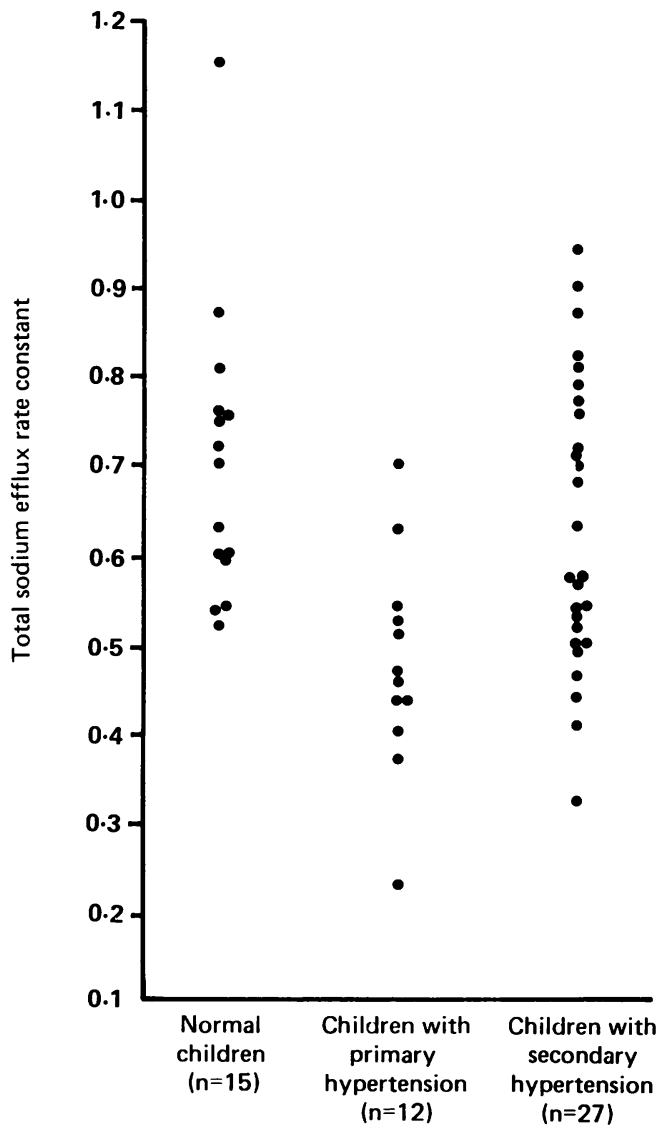

Fig 2 Total sodium efflux rate constants in erythrocytes from normal children, children with primary hypertension, and children with secondary hypertension.

control children $(6.6(0.32) \mathrm{mmol} / \mathrm{l}$ cells $)$, and in children with secondary hypertension $(6.7(0.26)$ $\mathrm{mmol} / \mathrm{l}$ cells $)(\mathrm{p}<0.05)$ (fig 1$)$. In children with primary hypertension, mean total sodium efflux rate constant was significantly lower $(0 \cdot 5071(0 \cdot 04))$ than in control children $(0.6983(0.04))$, and in children with secondary hypertension $(0.6197(0.03))$ $(\mathrm{p}<0.001)$ (fig 2$)$. The mean maximum binding of ouabain to erythrocytes that reflects the number of pump receptor sites was reduced in children with primary hypertension $(9.1(0.45) \mathrm{nmol} / \mathrm{l}$ cells) compared with controls $(11.7(0.73) \mathrm{nmol} / \mathrm{l}$ cells), and with those with secondary hypertension (11.0 (0.49) $\mathrm{nmol} / \mathrm{l}$ cells $)(\mathrm{p}<0 \cdot 005)($ fig 3$)$.

\section{Discussion}

There are several pathways for active transport of sodium in erythrocytes. Firstly, there is sodium/ lithium countertransport, which is equivalent to sodium/sodium countertransport. This channel is thought to exchange a single external sodium ion for a single internal one. This cannot affect the overall distribution of sodium across cell membranes and there is, therefore, some doubt about its physiological role. ${ }^{9}$ Canessa et al,${ }^{10}$ however, reported that countertransport was increased in erythrocytes in patients with essential hypertension, suggesting that this system could be a marker for essential hypertension.

The second system that has been studied is frusemide sensitive sodium/potassium cotransport. This pathway lies dormant in the cell membrane unless intracellular sodium concentrations rise above a critical point, and acts as a supporting mechanism for sodium extrusion. Garay et al reported that the activity of this system was decreased in erythrocytes of patients with essential hyper-

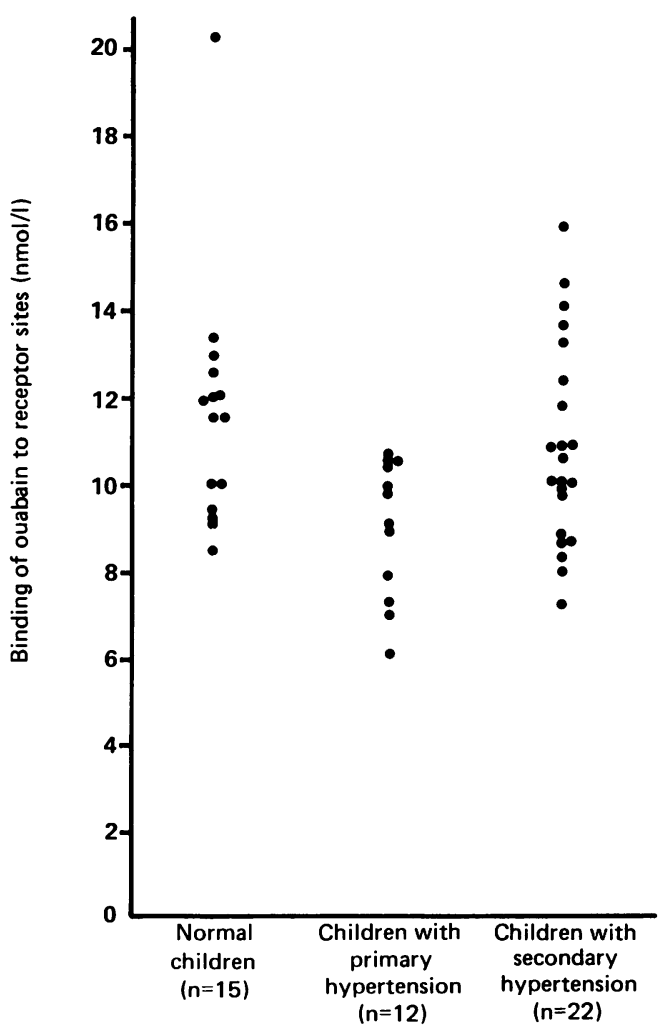

Fig 3 Binding of ouabain to erythrocytes representing pump receptor sites in normal children, children with primary hypertension, and children with secondary hypertension. 
tension, suggesting that this system could also be a marker for essential hypertension. ${ }^{11}$

A third system is the sodium pump, which is the best described and most widely studied pathway for cellular sodium homoeostasis. The activity of the pump system is consistently low in white cells of adult patients with essential hypertension, ${ }^{12}{ }^{13}$ but inconsistent results have been obtained in erythrocytes that are thought to be caused by the activity of the pump being much slower in erythrocytes than in white cells. ${ }^{9}$ It was impossible to study white cells in children, however, because more than $100 \mathrm{ml}$ of blood would be required for each assay, so we chose to study erythrocytes by measuring erythrocyte intracellular sodium concentration, total sodium efflux rate constant and maximum binding of ouabain to erythrocytes instead of sodium/lithium counter-transport or sodium/potassium cotransport.

Few studies have been undertaken on erythrocyte sodium transport in children with primary hypertension. Mongeau ${ }^{56}$ reported that children with labile hypertension tended to have decreased sodium/potassium cotransport and those with stable hypertension increased countertransport. Although interesting, however, these findings may not contribute to our understanding of the mechanisms concerned in developing hypertension, because the methods used for measuring sodium transport either reflect activity of a system with little physiological importance or rely on laboratory induced unphysiological conditions.

In the present study eight children with secondary hypertension were receiving antihypertensive drugs (captopril, propranolol, or hydralazine). We did not find any differences in erythrocyte sodium transport between two groups of children receiving or not receiving hypotensive treatment, even though the drugs used have been reported to have some effect on sodium transport across the cell membranes in adults. ${ }^{14}$ The children who acted as controls were age matched with the children with secondary hypertension, but the children with primary hypertension were a little older. We have not, however, observed any differences in erythrocyte sodium transport associated with age in children after infancy. Differences in age and medication were therefore negligible among the three study groups.

Our findings that children with primary hypertension had significantly higher erythrocyte intracellular sodium concentration and significantly lower total sodium efflux rate constant and maximum binding of ouabain to erythrocytes than control children and children with secondary hypertension, confirm results reported by workers studying adults with hypertension. It seems likely that the high erythrocyte intracellular sodium concentration seen in children with primary hypertension is a result of low total sodium efflux rate constant caused by the small number of sodium pump sites.

These findings suggest that measurements of erythrocyte intracellular sodium concentration, total sodium efflux rate constant, and maximum binding of ouabain to erythrocytes may have some diagnostic value in positively identifying children with primary as opposed to secondary hypertension, and may have a predictive value in identifying children who are at risk of developing essential hypertension in adult life. There is, however, substantial overlap among the groups of patients and further study is currently being undertaken to establish whether factors such as a family history of essential hypertension play a part in modifying transport of electrolytes across cell membranes. It is not yet known whether the erythrocyte sodium transport defect is caused by the hypertension, is a cause of the hypertension, or is just a marker. ${ }^{9}$

We thank Dr H Bobinski of Manchester University, Dr PL Weissberg of the Queen Elizabeth Hospital, Birmingham, and $\mathrm{Dr}$ G Sagnella of the Charing Cross Hospital Medical School, London, for their technical advice. This work was suppported by the Kidney Research Aid Fund, Charlotte Parkinson Research Fund, ER Squibb and Sons Ltd, John Herring and Friends, and the Child Health Research Appeal Trust.

\section{References}

1 Losse H, Wehmeyer H, Wessels F. Wasser-und Elektrolytgehalt von Erythrozyten bei arterieller Hypertonie. Klin Wochenschr 1960;38:393-5.

2 Tosteson DC, Adragna N, Bize I, Solomon H, Canessa M. Membranes, ions and hypertension. Clin Sci 1981;61(suppl 7): 5-10s.

3 Anonymous. Cells, ions and blood pressure. Lancet 1982;ii: 965-7.

4 Postnov YV, Orlov SN. Cell membrane alteration as a source of primary hypertension. J Hypertens 1984;2:1-6.

5 Mongeau JG. Value of measurement of erythrocyte cation fluxes as a genetic marker in essential hypertension of adolescents and children. In: Brodehl J, Ehrich JHH, eds. Paediatric nephrology. Berlin: Springer-Verlag, 1984:382-4.

6 Mongeau JG. Erythrocyte cation fluxes in essential hypertension of children and adolescents. Int J Pediatr Nephrol 1985;6:41-6.

${ }^{7}$ Fitzgibbon WR, Morgan TO, Myers JB. Erythrocyte ${ }^{22} \mathrm{Na}$ efflux and urinary sodium excretion in essential hypertension. Clin Sci 1980;59:195s-7.

${ }^{8}$ Gardner JD, Conlon TP. The effects of sodium and potassium on ouabain binding by human erythrocytes. J Gen Physiol 1972;60:609-29.

9 Weissberg PL. Ion transport studies-technical problems. J Hypertens 1983;1 (suppl 2):395-7.

${ }^{10}$ Canessa M, Adragna N, Solomon HS, Connoly TM, Tosteson DC. Increased sodium-lithium countertransport in red cells of patients with essential hypertension. $N$ Engl J Med 1980;302:772-6.

11 Garay RP, Elghozi JL, Dagher G, Meyer P. Laboratory 
distinction between essential and secondary hypertension by measurement of erythrocyte cation fluxes. N Engl J Med 1980; 302:769-71.

12 Edmondson RPS, Thomas RD, Hilton PM, Patrick J, Jones NF. Abnormal leucocyte composition and sodium transport in essential hypertension. Lancet 1975;i:1003-5.

13 Poston L, Sewell RB, Wilkinson SP, et al. Evidence for a circulating sodium transport inhibitor in essential hypertension. Br Med J 1981;282:847-9.
14 Thomas RD, Edmondson RPS, Hilton PJ, Jones NF. Abnormal sodium transport in leukocytes from patients with essential hypertension and the effect of treatment. Clinical Science and Molecular Medicine 1975;48:169s-70.

Correspondence to Dr MJ Dillon, Renal Unit, Hospital for Sick Children, Great Ormond Street, London WC1 3JH.

Accepted 11 August 1988 